\title{
Philosophiques
}

\section{Livres reçus (printemps 2009)}

Volume 36, numéro 1, printemps 2009

L’idéalisme britannique

URI : https://id.erudit.org/iderudit/038028ar

DOI : https://doi.org/10.7202/038028ar

Aller au sommaire du numéro

Éditeur(s)

Société de philosophie du Québec

ISSN

0316-2923 (imprimé)

1492-1391 (numérique)

Découvrir la revue

Citer ce document

(2009). Livres reçus (printemps 2009). Philosophiques, 36(1), 271-272.

https://doi.org/10.7202/038028ar

Ce document est protégé par la loi sur le droit d'auteur. L'utilisation des services d'Érudit (y compris la reproduction) est assujettie à sa politique d'utilisation que vous pouvez consulter en ligne.

https://apropos.erudit.org/fr/usagers/politique-dutilisation/
Cet article est diffusé et préservé par Érudit.

Érudit est un consortium interuniversitaire sans but lucratif composé de l’Université de Montréal, l'Université Laval et l'Université du Québec à Montréal. Il a pour mission la promotion et la valorisation de la recherche. https://www.erudit.org/fr/ 


\section{Livres reçus (printemps 2009)}

Bloch, Ernst, "Symbole : les Juifs. " Un chapitre oublié de L'esprit de l'utopie, précédé de Lellouche, Raphaël "Les Juifs dans l'utopie ", traduit de l'allemand par Raphaël Lellouche, Combas, Éditions de l'Éclat, 2009, 176 p.

Botet, Serge, Petit traité de la métaphore. Un panorama des théories modernes de la métaphore, Strasbourg, Presses universitaires de Strasbourg, 96 p.

Boulad-Ayoub, Josiane et Torero-Ibad, Alexandra (dir.), Matérialismes des modernes. Nature et mours, Québec, Presses de l'Université Laval, 2009, 347 p.

Brandom, Robert, Between Saying and Doing: Towards an Analytic Pragmatism, Oxford, Oxford University Press, 2008, $251 \mathrm{p}$.

Bühler, Karl, Théorie du langage, traduit et annoté par Didier Samain, présenté par Janette Friedrich avec une préface de Jacques Bouveresse, Marseille, Agone, collection "Banc d'essais ", 688 p.

Cossette, Claude. Éthique et publicité, Presses de l'Université Laval, 2009, 148 p.

Fillion, Réal, La dynamique multiculturelle et les fins de l'Histoire, Ottawa, les Presses de l'Université d'Ottawa (coll. : Philosophica), 2008, 205 p.

Habermas, Jürgen, Entre naturalisme et religion. Les défis de la démocratie, trad. de l'allemand par Christian Bouchindhomme et Alexandre Dupeyrix, 400 pages, Paris, Gallimard (Collection NRF Essais), 400 p.

Lacroix, André, Critique de la raison économiste. La raison n'est pas une science morale, Montréal, Liber, 2009, 184 p.

Moreau, Denis, Taranto, Pascal (dir.), Activité physique et exercices spirituels. Essai de philosophie du sport, Paris, Vrin (coll. : Pour Demain), 2009, 246 p.

Nadeau, Christian, Saada, Julie, Guerre juste, guerre injuste. Histoire, théories et critiques, Paris, PUF (coll. : Philosophies), 2009, 153 p.

Nadeau, Christian, Justice et démocratie. Une introduction à la philosophie politique, Montréal, Presses de l'Université de Montréal (coll. : Paramètres), 186 p.

Owen, Ruwen, La vie, la mort, l'état. Le débat bioéthique, Paris, Grasset (coll. : Mondes vécus), 2009, $221 \mathrm{p}$.

Perinetti, Dario, Ricard, Marie-Andrée (dir.), La Phénoménologie de l'esprit de Hegel : lectures contemporaines, Paris, PUF (coll. : fondements de la politique), 2009, $232 \mathrm{p}$.

Rousseau, Jean-Jacques, Discours sur l'origine et les fondements de l'inégalité parmi les hommes, Présentation et notes par Blaise Bachofen et Bruno Bernardi, Paris, Flammarion (coll. : GF), 302 p.

Theis, Robert, Jonas. Habiter le monde, Paris, Michalon, (coll. : « Le bien commun »), 2008, 122 p.

Outre les ouvrages qui apparaissent dans cette liste, la rédaction de Philosophiques peut obtenir, pour fin de compte rendu ou d'étude critique, la plupart des livres parus récemment. 
Les personnes désireuses de faire un compte rendu ou une étude critique sont priées de s'adresser à :

\section{Guillaume Fréchette}

Philosophiques

Département de philosophie

Université du Québec à Montréal

c.p. 8888 , succ. Centre-ville

Montréal, Qc

H3C 3P8

frechette.guillaume@uqam.ca 